\title{
An Evaluation of Radar-Based Tornado Track Estimation Products by Oklahoma Public Safety Officials $\mathscr{}$
}

\author{
Charles M. Kuster, ${ }^{a, b, c}$ PAMEla L. Heinselman, ${ }^{b, c}$ JefFrey C. SNyder, ${ }^{a, b, c}$ \\ Katie A. Wilson, ${ }^{\mathrm{a}, \mathrm{c}}$ DOUglas A. Speheger, ${ }^{\mathrm{d}}$ AND JAMES E. Hocker ${ }^{\mathrm{e}}$ \\ ${ }^{a}$ Cooperative Institute for Mesoscale Meteorological Studies, Norman, Oklahoma \\ ${ }^{\mathrm{b}}$ NOAA/OAR/National Severe Storms Laboratory, Norman, Oklahoma \\ ${ }^{\mathrm{c}}$ University of Oklahoma, Norman, Oklahoma \\ ${ }^{\mathrm{d}}$ NOAA/National Weather Service, Norman, Oklahoma \\ e Oklahoma Climatological Survey, Norman, Oklahoma
}

(Manuscript received 9 March 2017, in final form 2 June 2017)

\begin{abstract}
Many public safety officials (e.g., emergency managers and first responders) use weather-radar data to inform many life-saving decisions, such as sounding outdoor warning sirens and directing storm spotters. Therefore, to include this important user group in ongoing radar applications research, a knowledge coproduction framework is used to interact with, learn from, and provide information to public safety officials. From these interactions, it became clear that radar-based products that estimate a tornado's location, intensity, or both could be valuable to public safety officials. Therefore, a survey was conducted and a focus group formed to 1) collect feedback on several of these products currently under development, 2) identify potential decisions that could be made with these products, and 3) examine the impact of radar update time on product usefulness. An analysis of the survey and focus group responses revealed that public safety officials preferred simple interactive products provided to them using multiple communication methods. Once received, any product that could clearly communicate where a tornado may have occurred would likely help public safety officials focus search and rescue efforts in the immediate aftermath of a tornado. Additionally, public safety officials preferred products created using rapidupdate data (1-2-min volumetric updates) over conventional-update data (4-5-min volumetric updates) because it provided them with more complete information.
\end{abstract}

\section{Introduction}

Many public safety officials (e.g., emergency managers and first responders) use weather-radar data to support decisions ranging from directing storm spotters to coordinating search and rescue efforts (e.g., Morris et al. 2002; Baumgart et al. 2008; Weaver et al. 2014). In a national survey of approximately 900 public safety officials working in the United States, Weaver et al. (2014) found that $30.3 \%$ of respondents would activate their emergencyresponse system based solely on Doppler radar evidence of a tornado. This percentage increased as more data (e.g., law enforcement reports) became available and the storm

Supplemental information related to this paper is available at the Journals Online website: https://doi.org/10.1175/ WAF-D-17-0031.s1.

Corresponding author: Charles M. Kuster, charles.kuster@noaa. gov got closer to the respondent's area of responsibility. Research in Oklahoma has provided additional insight into how public safety officials access and use radar data. League et al. (2010) analyzed results from a survey distributed to 62 Oklahoma public safety officials and found that $86 \%$ of respondents used radar data every few minutes during severe weather events. Respondents reported accessing radar data most commonly through the National Weather Service (NWS) website and the Oklahoma First-Response Information Resource System using Telecommunications (OK-FIRST; Morris et al. 2002) that has provided radar training to over 1300 public safety officials since it began in 1996 .

To determine how public safety officials use radar data, Baumgart et al. (2008) presented 11 Oklahoma public safety officials with a questionnaire about radar use and decisions typically made during severe weather events. The participants then interacted with radar data in a simulated real-time case and vocalized their thought process while working the case. After analyzing the 
data, researchers determined that public safety official use of radar data consisted primarily of looking at lowlevel reflectivity and velocity data to assess storm location, movement, size, and intensity. This information then supported decisions such as activating outdoor warning sirens, evacuating a local airport, and routing search and rescue teams around dangerous storms (e.g., Morris et al. 2002; Baumgart et al. 2008; League et al. 2010).

Since public safety officials are an important user of radar data in Oklahoma and across the United States, it is crucial to include them in the development of new weather radar technology and products. One example of ongoing collaborations includes researchers working with NWS forecasters and public safety officials to evaluate probabilistic hazard information (e.g., Stumpf et al. 2008; Karstens et al. 2015) in an experiment that aims to simulate the real-time working environment of an integrated warning team (LaDue et al. 2016). Another collaboration process, called coproduction of knowledge (e.g., Jasanoff and Wynne 1998; Lemos and Morehouse 2005; Meadow et al. 2015), provides a framework for expanding ongoing collaborations between meteorologists working at the National Weather Center and public safety officials to include radar data applications. This process emphasizes collaboration between scientists and stakeholders through relationship building and two-way communication to produce information that is understandable and easily accessible by decision-makers (e.g., Jasanoff and Wynne 1998; Meadow et al. 2015). Coproduction studies can involve different levels of stakeholder engagement with higher levels more likely to produce usable information because stakeholders act as partners during the research process. The four primary modes of engagement in order of stakeholder involvement are 1) contractual, 2) consultative, 3 ) collaborative, and 4) collegial (Biggs 1989; Meadow et al. 2015).

To further engage public safety officials in the development of new radar technology and radar-based products, we adopted the collaborative mode of engagement, which emphasizes building long-term relationships and continuous stakeholder involvement (e.g., Meadow et al. 2015). Therefore, two-way relationships were built with members of the public safety official community by attending their monthly meetings, annual workshops, and conferences, as well as engaging in dozens of face-to-face conversations. This ongoing relationship building provided an opportunity to learn about the daily duties of public safety officials during days with severe weather, determine common uses of radar data, identify knowledge gaps and potential research needs based on stakeholder knowledge, and share information about ongoing weather-related research at the National Weather Center. During this first step of stakeholder engagement, multiple public safety officials mentioned a need for a product that could clearly indicate where a tornado had occurred. Knowing that development of these products had already begun, there was an immediate need to involve public safety officials in the ongoing development of products that estimate a tornado's location, intensity, or both [hereafter referred to as tornado track estimation products; e.g., Manross et al. (2008); Snyder and Ryzhkov (2015); Karstens et al. (2016)]. Therefore, the purpose of this study was to ensure that public safety official's ideas were considered by product developers by gathering information from public safety officials regarding their tornado track estimation product preferences and the decisions they might make with the support of these products.

To obtain this information, we leveraged the relationships built with many Oklahoma public safety officials to distribute a weather-radar survey using a snowball sampling technique (e.g., Biernacki and Waldorf 1981) in which each respondent is encouraged to send the survey link to fellow colleagues. A focus group was also conducted to address some limitations of the survey and collect more specific feedback from a subset of Oklahoma public safety officials. Questions posed to survey and focus group participants focused on three key topics of interest: 1) typical use of radar data on a day with severe weather, 2) respondents' perceptions of five tornado track estimation products - two created manually and three created automatically-currently under development that could become operational in the future, and 3) examples of how these products could support decisions in the immediate aftermath of a tornado. This portion of our overarching study is more representative of the consultative mode of engagement (Biggs 1989; Meadow et al. 2015), in which stakeholders are involved at specific stages to inform and guide research efforts. However, the survey and focus group also further our overall collaborative research efforts because the provided responses will ultimately help researchers share understandable and easily accessible information and products with public safety officials.

This paper describes five tornado track estimation products (section 2) and the methods by which feedback was collected from public safety officials (section 3). Feedback collected via the survey and focus group is outlined in section 4 and then discussed within the context of applications to meteorological research (section 5). 


\section{Radar estimation of tornado track and intensity}

The weather-radar survey and focus group activities presented public safety officials with five tornado track estimation products: 1) NWS track, 2) tornado track and intensity, 3) rotation track, 4) maximum Doppler velocity track, and 5) tornado debris signature (TDS). The first two aforementioned products are manually generated (Fig. 1) while the last three are automatically generated by algorithms (Fig. 2). All product examples included in the survey and focus group were created using a dual-polarization research Weather Surveillance Radar 1988-Doppler (WSR-88D) located in Norman, Oklahoma (KOUN). This radar can perform $90^{\circ}$ sector scans, which result in volumetric update times of less than $2 \mathrm{~min}$, increasing the utility of the data it collects for evaluating tornado track estimation products. Each product is currently experimental, but preliminary versions of the NWS track and rotation track products are available for operational use (e.g., Miller et al. 2013).

Various radar limitations such as spatial resolution (e.g., Brown et al. 1978) and aspect ratio (e.g., Burgess et al. 1993) prevent most of the products discussed here from detecting the tornado itself. These products instead indicate tornado location and perhaps intensity based on features more readily detected by WSR-88D radars (e.g., mesocyclones and tornado vortex signatures), along with the aid of NWS forecaster input and spotter reports. In addition, radar detects features at beam height, not necessarily very near the ground where damage occurs (e.g., Speheger and Smith 2006). These factors limit product usefulness with increasing range, since a radar's accuracy in depicting near-surface conditions decreases with increasing range (Fig. 3). Therefore, conditions at the surface could be different than what the products depict and should be applied with caution by users far (i.e., over about $100 \mathrm{~km}$ ) from the nearest radar. In addition, the TDS product is only created when the radar beam (3-dB beamwidth) is below the melting layer and therefore may not be available to users far from the nearest radar.

\section{a. NWS track}

In 2012, the Norman NWS Forecast Office developed a manually generated product specifically designed for public safety officials. A tool allows forecasters to produce preliminary tornado damage paths by tracking the location of a tornadic velocity couplet in quasi real time. Using this tool, a forecaster can mark the position of a velocity couplet in the Advanced Weather Interactive Processing System (AWIPS) over time. These points are used to generate a Keyhole Markup

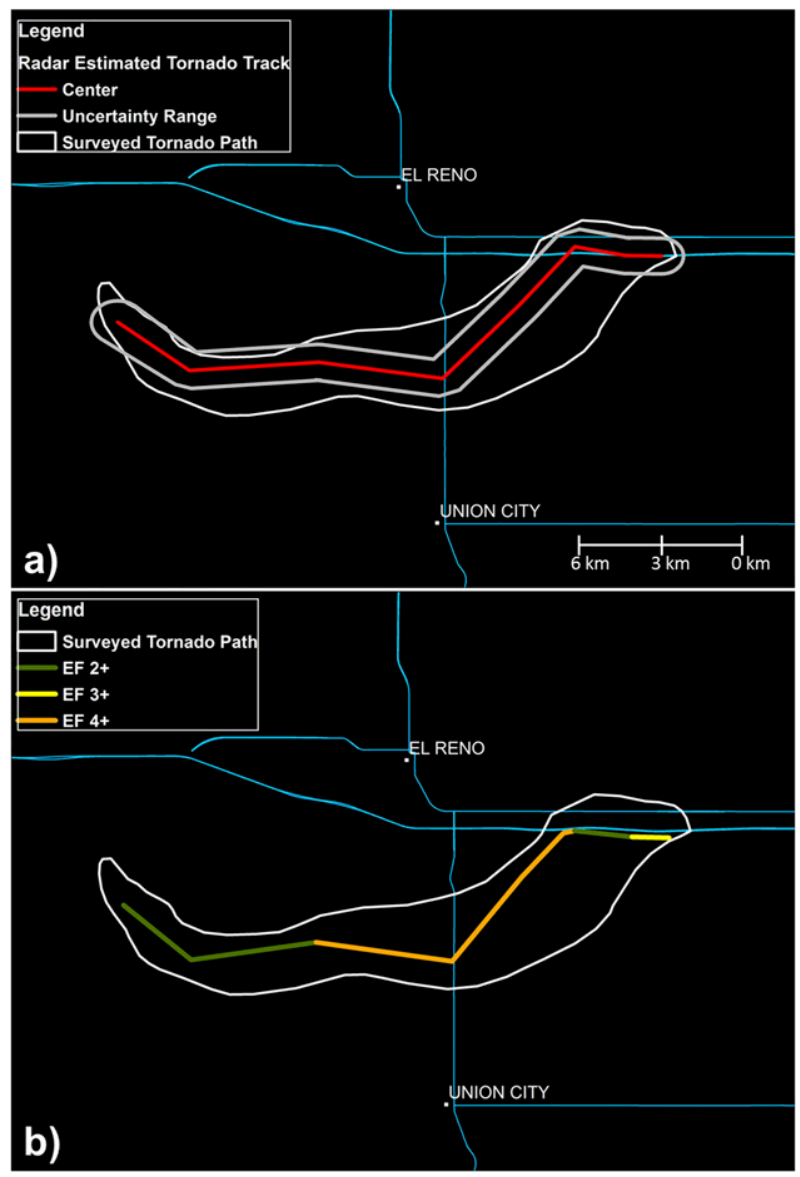

FIG. 1. Manually generated products with example of (a) NWS track and (b) tornado track and intensity. The irregular white outline is the surveyed tornado damage path provided by the NWS Forecast Office in Norman and is included for comparison with each product's performance. Blue lines represent major roadways. Products were created using data from an EF3 tornado that occurred in central OK on 31 May 2013. In (a), the red line is the radar-based tornado centerline estimate, and the curved gray outline is the uncertainty bound. In (b), the colored line is the radar-based tornado centerline estimate, where the color represents the potential damage intensity based upon the estimated wind speeds. The tornado's range from radar varies from about 46 to $62 \mathrm{~km}$.

Language (KML) file that shows an estimation of the tornado's centerline track along with uncertainty bounds (Fig. 1a). The uncertainty bounds are based on ongoing research at the Norman NWS Forecast Office similar to that of Speheger and Smith (2006), in which radar-estimated tornado locations were compared to ground-surveyed locations for 240 tornadoes across the United States between 2009 and 2016. Analysis of the results (Fig. 3) shows that the uncertainty distance (i.e., distance between radar-estimated location and actual location) is about one-half of that shown in Speheger and Smith (2006) thanks to recent radar advancements 

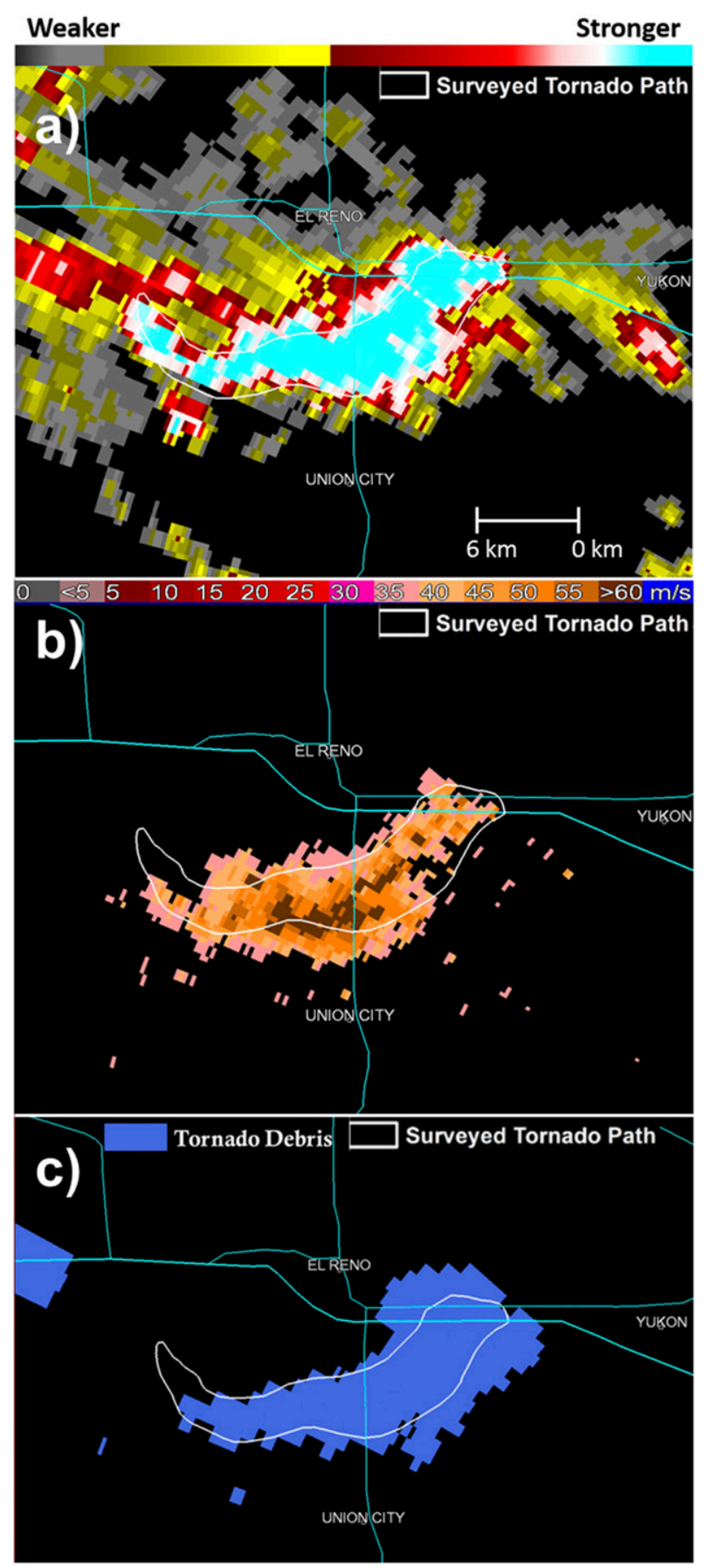

FIG. 2. Automatically generated products with example of (a) rotation track, (b) maximum Doppler velocity track, and (c) TDS. The irregular white outline is the surveyed tornado damage path provided by the NWS Forecast Office in Norman and is included for comparison with each product's performance. Blue lines represent major roadways. Products were created using data from an EF3 tornado that occurred in central OK on 31 May 2013. In (b), the minimum velocity threshold is $35 \mathrm{~m} \mathrm{~s}^{-1}$. The tornado's range from radar varies from about 46 to $62 \mathrm{~km}$. such as superresolution data (e.g., Wood et al. 2001; Brown et al. 2002; Brown and Wood 2012) and improved filtering of side-lobe contamination (Piltz and Burgess 2009). This updated uncertainty distance provides the basis for the NWS track's uncertainty bounds, which represent radar-based location uncertainty as a function of the velocity couplet's distance from the radar. The centerline of the observed tornado lies within the uncertainty bounds $90 \%$ of the time.

The accuracy of the preliminary paths can be improved by the forecaster's consideration of other data sources (e.g., environmental parameters, spotter reports, and information from local media), recognition of radar limitations (e.g., beam broadening), and past operational experience. While the paths are not produced for all velocity couplets, if a tornado is observed and significant impacts are anticipated, a forecaster can choose to use the tool. For example, the product was created shortly after the 20 May 2013 tornado that occurred in the Oklahoma City, Oklahoma, metropolitan area (e.g., Burgess et al. 2014) and was used by the Federal Emergency Management Agency to identify locations in need of resources (e.g., Karstens et al. 2016).

\section{b. Tornado track and intensity}

The authors generated a second manually created product that estimates a tornado's location and intensity based on encouraging results from previous studies that found a relationship between low-level Doppler velocity observations and a tornado's enhanced Fujita (EF) scale rating (e.g., Doswell et al. 2009; LaDue et al. 2012; Toth et al. 2013; Kingfield and LaDue 2015; Smith et al. 2015). Specifically, intensity estimates were determined using a velocity couplet's rotational velocity and the conditional probability of tornado damage intensity presented in Smith et al. (2015). The product can likely be produced similarly to the NWS track in that an NWS forecaster could track the location of a tornadic velocity couplet and measure the couplet's rotational velocity with time in AWIPS. The resulting product could contain a line showing the tornado's approximate location that is color coded based on the intensity estimate (Fig. 1b). Though not included here, uncertainty bounds could likely be added similarly to the NWS track.

\section{c. Rotation track}

This automated product (Fig. 2a) was developed to aid NWS forecasters and emergency managers during postevent assessments (Manross et al. 2008). Radar data from the Multi-Radar Multi-Sensor system (e.g., Zhang et al. 2016) are used to produce a gridded product depicting the maximum values of azimuthal shear (i.e., rotational intensity) in the lowest $2 \mathrm{~km}$ accumulated 


\section{Distance Between Radar Rotation Center and Surveyed Damage Path vs. Distance From Radar}

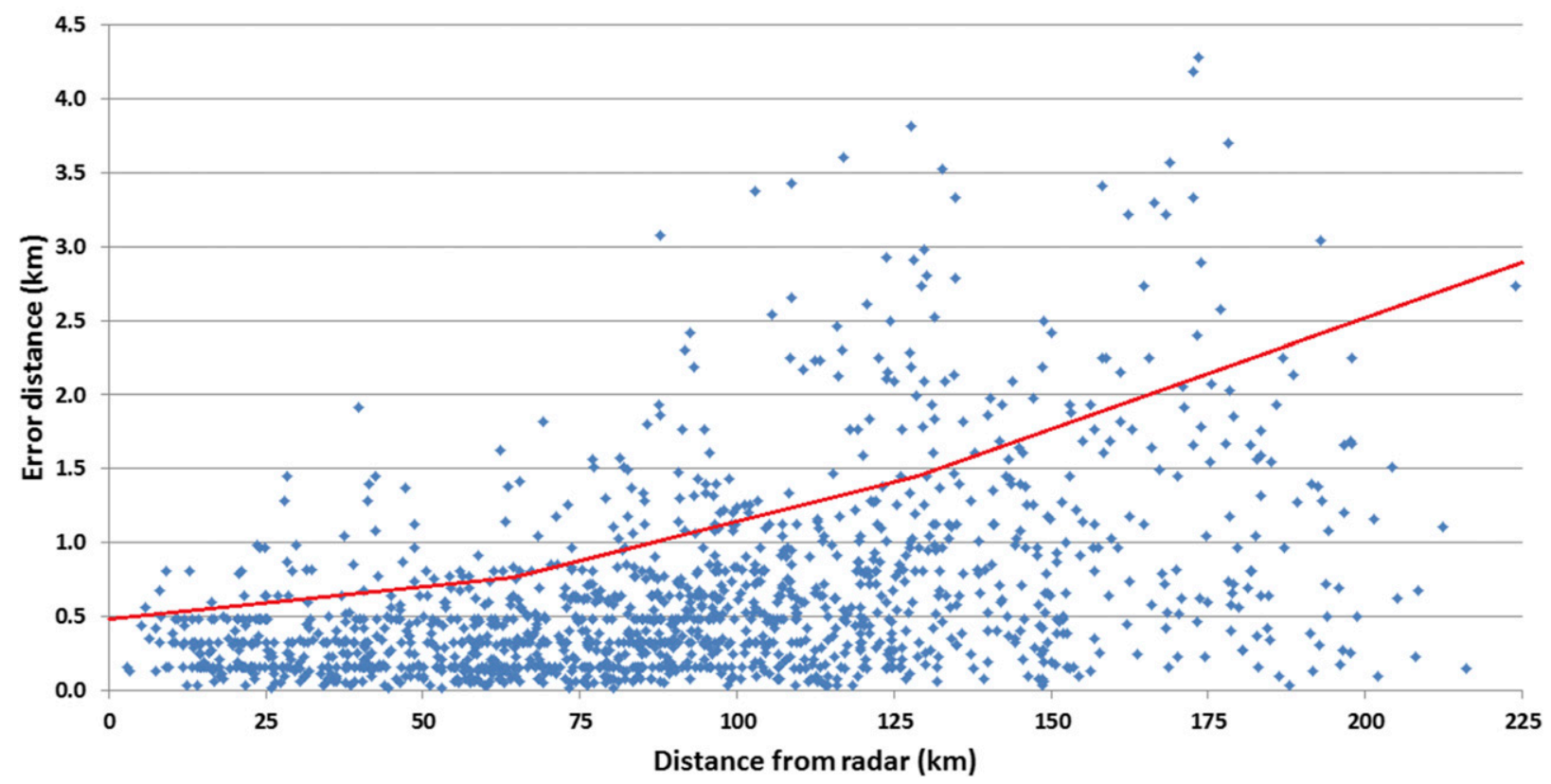

FIG. 3. Distance between the radar-based estimation of tornado location and the actual location based on NWS damage surveys as a function of a tornado's range from the radar. Data are from 2009 to 2016 . Red line is the $90 \%$ confidence level that is used to draw the uncertainty bounds included in the NWS track. [This figure is an updated version of Fig. 3 in Speheger and Smith (2006).]

over time (e.g., Manross et al. 2008; Karstens et al. 2016). The product has undergone improvements since its creation in 2007 including quality controlling reflectivity data to account for nonmeteorlogical echoes, applying a range correction algorithm to lessen the impacts of beam widening with increasing range, and eliminating relatively low background values of azimuthal shear to highlight the stronger values likely associated with mesocyclones (Miller et al. 2013). This product has been used by NWS forecast offices for damage survey planning and by the American Red Cross for disaster resource allocation (Manross et al. 2008; Miller et al. 2013). In this study, we used $0.5^{\circ}$ elevation angle data from KOUN to create the rotation tracks.

\section{d. Maximum Doppler velocity track}

This automated product was developed by the authors for this study as a proof of concept to depict the scope (i.e., location, width, and magnitude) of strong winds associated with a tornado or other damaging thunderstorm winds (e.g., downbursts and rear-flank downdrafts). To produce the product, the $0.5^{\circ}$ velocity field is used to calculate the maximum absolute radial velocity over a specified time period. Currently, the user must manually specify a minimum threshold to filter out lower Doppler velocities less likely to be associated with the tornado or damaging winds. This minimum threshold would likely vary by case depending on factors such as the range from the radar and mesocyclone intensity and could, therefore, be challenging to determine in real time. Therefore, automation of this threshold identification process is likely needed for any future operational product. The product presented in the weather-radar survey depicts the maximum radial Doppler velocity at every radar range gate over time and had a minimum velocity threshold of $35 \mathrm{~m} \mathrm{~s}^{-1}$ (Fig. 2b).

\section{e. $T D S$}

Van Den Broeke and Jauernic (2014) showed that $16 \%$ of the 744 tornadoes they studied produced a TDS, but $88.2 \%$ of tornadoes rated EF3 $(n=17)$ and $100 \%$ of tornadoes rated EF4 or EF5 $(n=7)$ were associated with a TDS. Considering the strong association between the appearance of a TDS and the occurrence of strong to violent tornadoes, automatically detecting a TDS could provide useful information to forecasters and public safety officials. Snyder and Ryzhkov (2015) described this automated product that uses dual-polarization radar data and a modified version of the hydrometeor classification algorithm (HCA; Park et al. 2009) to identify 
areas of debris lofted by a tornado (i.e., the TDS). Classifying a TDS involves using fuzzy logic applied to five inputs: azimuthal shear, differential phase, reflectivity, differential reflectivity, and correlation coefficient. The algorithm calculates an aggregation value for each output classifier, the results of which are then used to determine the classifier returned by the HCA at each range gate. In general, the algorithm returns the output classifier with the maximum aggregation value, given that it is at least 0.40 (otherwise, an "unknown" classification is returned). To reduce false detections, the TDS algorithm requires an aggregation value of at least 0.80 . By isolating the range gates for which a TDS is assigned and accumulating this classification with time, near-real-time tornado paths can be produced based on locations within the storm characterized by strong rotation and lofted debris (Fig. 2c).

\section{Weather-radar survey and focus group design}

Our online weather-radar survey consisted of 28 questions, over half (17) of which were open ended (see supplemental material available online). To provide context to the responses, the survey began with basic background questions such as how long the respondent had worked in public safety, how often they used radar data during severe weather events, and examples of decisions they had made in the past with the support of radar data. The next section provided the respondents with a short description of each product and an example of each using data from a tornado rated as $\mathrm{EF}^{1}{ }^{1}$ that occurred in central Oklahoma on 31 May 2013 (e.g., Snyder and Bluestein 2014; Bluestein et al. 2015). Respondents were asked how likely they were to use the product and what they liked and disliked about it (Fig. 4). At the beginning of this section, participants were also made aware that these products would not be available until after a tornado had developed (i.e., the products were not a forecast). Respondents were then asked to provide examples of decisions a tornado track estimation product could help them make and to rank the products from best to worst in terms of usefulness. They were also prompted to provide their reasoning for their rankings.

The link to the online survey was active from 21 April through 13 June 2016, and we received 182 responses during that time. Of the 182 responses, 138 were from Oklahoma, 16 from Wisconsin, 5 from Illinois, and fewer than 5 each from 12 additional states (Fig. 5a). Just over 100 respondents identified themselves as emergency

\footnotetext{
${ }^{1}$ A mobile radar sampled maximum radial velocity values as high as $135 \mathrm{~m} \mathrm{~s}^{-1}$ [302 $\mathrm{mi} \mathrm{h}^{-1}$; Snyder and Bluestein (2014)].
}

managers, 28 self-identified as first responders, and the remaining 51 identified themselves as "other," which included positions such as 911 call center director, city manager, and emergency communications chief (Fig. 5b). All respondents used radar data in some way to aid in their decision-making process.

While the survey provided useful information, we did identify some limitations while analyzing the collected responses. The survey format only allowed for limited information to be communicated to the respondents (Fig. 4). This limited information can lead to confusion and likely resulted in some survey respondent's misconceptions about the tornado track estimation products (section 4). We therefore made some modifications to the focus group design to specifically address questions generated during the survey analysis and to enhance the communication and clarity of the products to the participants. During the focus group, which was held in early September 2016, we provided more detailed information (e.g., strengths and limitations) about each of the products. This approach allowed us to collect more thorough, specific, and informed feedback from a subset of six public safety officials working in central Oklahoma. These six participants were selected-based on willingness, availability, and interest-from a group of central Oklahoma public safety officials and represented county and city emergency management $(n=3$ and 2, respectively), as well as first responders $(n=1)$.

During the focus group, we also expanded on feedback collected from the survey by facilitating a discussion about radar update time (i.e., time between successive radar volume scans) because faster updates of low-level radar data are now available from operational radars (e.g., Crum et al. 2013; ROC 2014) and faster updates of volumetric data are potentially coming in the future (e.g., Zrnić et al. 2007; Heinselman and Torres 2011). To familiarize participants with rapid-update volumetric update times (about $1 \mathrm{~min}$ ), we showed examples collected by the single-polarization National Radar Testbed Phased Array Radar (Forsyth et al. 2005; Zrnić et al. 2007) and compared such data with examples of conventional volumetric update times (about 4-5 min) collected by the WSR-88D network. We then showed participants examples of the tornado track estimation products created using rapid-update data collected by KOUN and conventional-update data. Participants then answered questions about radar update time and its impacts on the tornado track estimation products.

\section{Public safety official feedback}

While the results presented here include all collected responses, it is important to remember that 138 of the 


\section{Product 2: Tornado Track}

Q13 This product shows the radar-estimated center location of the tornado and the range of uncertainty (i.e., tornado should be somewhere within the gray outline).

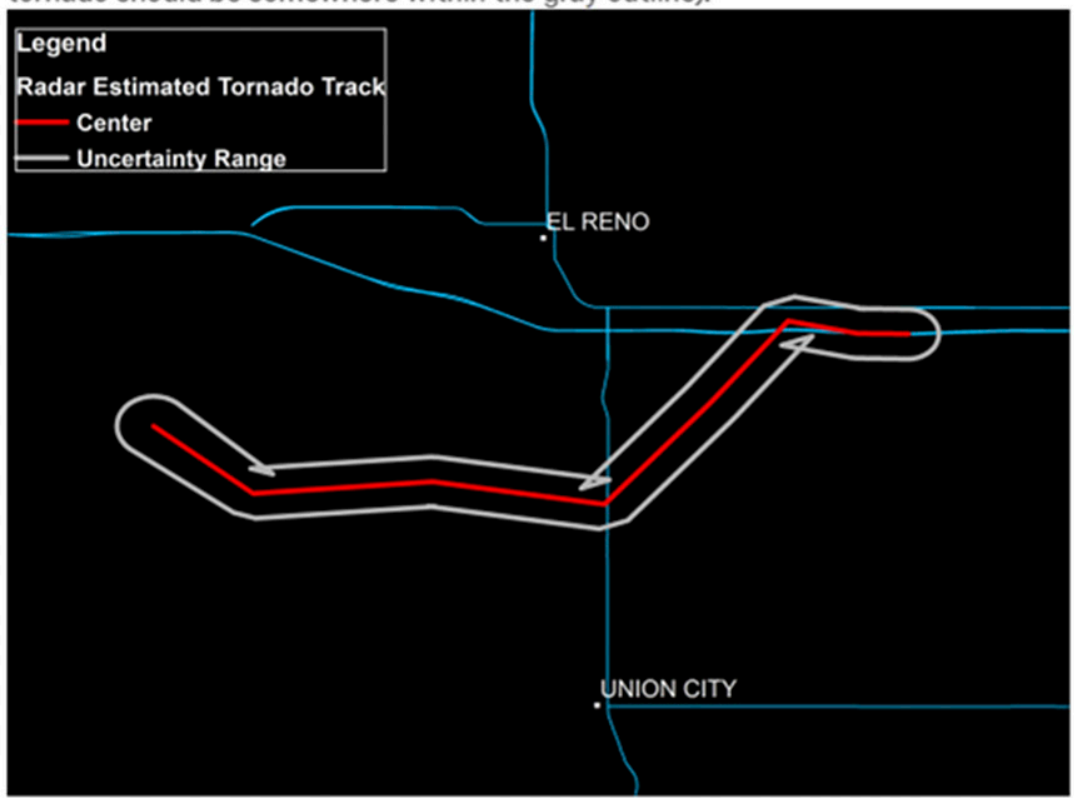

How likely are you to use this product if a tornado has recently occurred in your area? Please choose only one option.

\begin{tabular}{|c|c|c|c|c|c|}
\hline & \multicolumn{5}{|c|}{ Moderately } \\
\hline & Not at all likely & Slightly likely & likely & Very likely & Extremely likely \\
\hline
\end{tabular}

Likeliness

Please briefly describe what you like about this product.

Please briefly describe what you dislike about this product.

Q15

FIG. 4. Example of survey format and questions regarding tornado track estimation products. This example shows the NWS track section of the survey.

182 survey respondents and all focus group participants work in Oklahoma. There were no obvious major differences in the survey responses from those working in Oklahoma and those working outside of Oklahoma, but Oklahoma public safety officials may have more severe-weather-related experience and may also receive different radar-based training (e.g., OK-FIRST).
Therefore, the results are likely only generalizable to Oklahoma.

\section{a. Survey results}

Survey questions first sought to provide context to each respondent's feedback by asking about how often they use weather-radar data during severe weather 

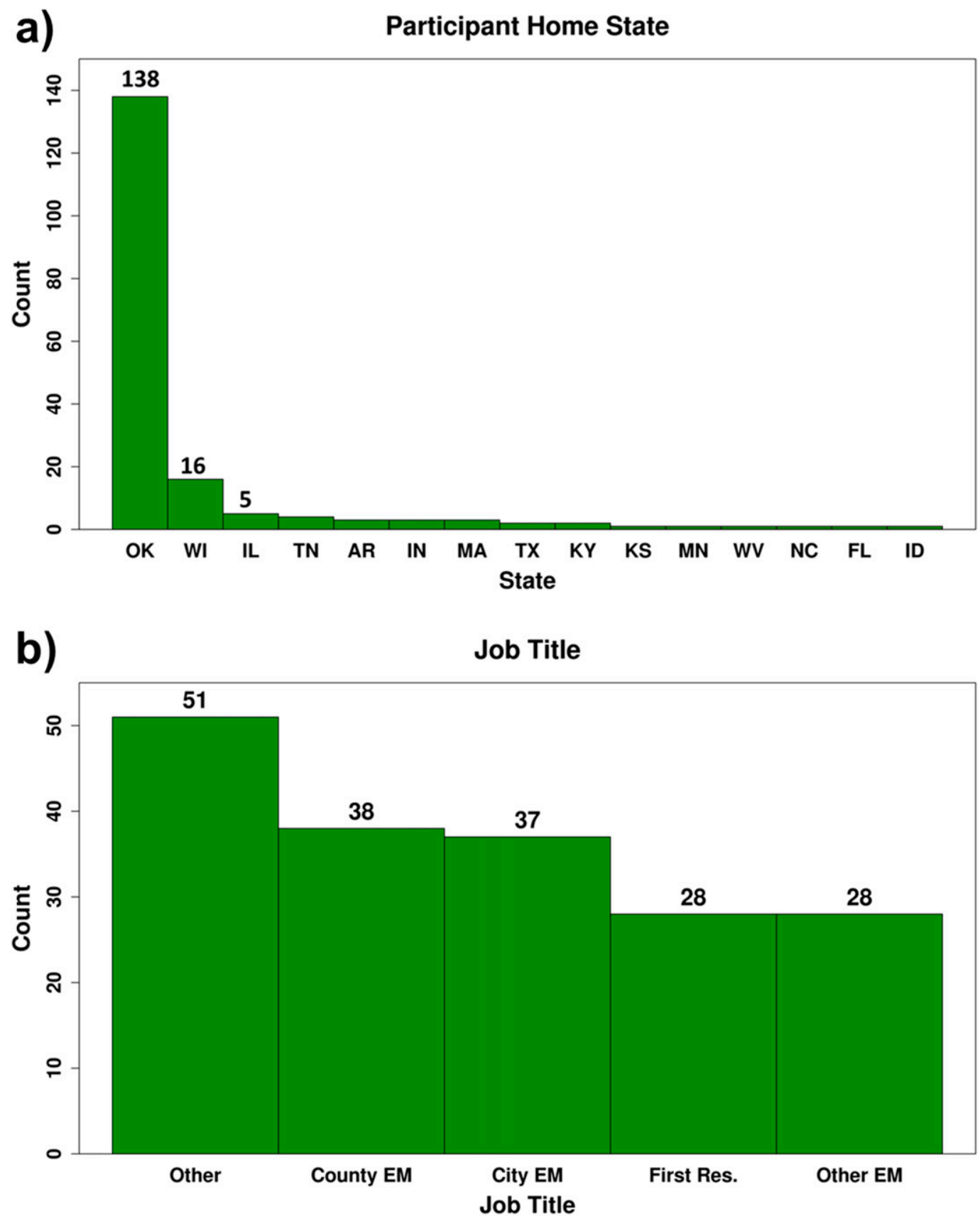

FIG. 5. Weather-radar survey participants broken down by (a) the state in which they work and (b) general job title, where EM stands for "emergency manager." The "other" category includes positions such as 911 call center director, city manager, and emergency communications chief.

events and how the data were used in the decisionmaking process. Nearly $80 \%(n=143)$ of survey respondents reported that they used radar data at least once every $10 \mathrm{~min}$ when severe weather threatened their area of responsibility. Only $6 \%(n=9)$ reported using radar data no more than once per hour during an event. Respondents provided a wide range of answers to the open-ended questions regarding radar data use, which reflects the wide range of responsibilities public safety officials have, but an analysis identified several common themes. The most common response $(n=78)$ for the use of radar data was determining a storm's motion, proximity, and intensity (i.e., storm interrogation). Other common responses included providing information to 
storm spotters and first responders $(n=40)$, and activating warning sirens $(n=15)$. These findings corroborate previous research results (e.g., Baumgart et al. 2008; Weaver et al. 2014).

We also asked an open-ended question about potential decisions that could be made with the support of a tornado track estimation product. Over half $(n=106)$ of the respondents indicated that these products would help them determine the disaster's scope and therefore aid in deciding where to send search and rescue teams and disaster-response resources. The products could help them narrow down the area potentially impacted by a tornado and therefore allow them to coordinate recovery efforts to specific areas more quickly. Other potential decisions that multiple respondents mentioned included identifying safe staging areas and transportation routes $(n=10)$ and checking on individual households and registered storm shelter locations within the damage path $(n=8)$.

Since respondents to this survey and previous research (e.g., Miller et al. 2013; Karstens et al. 2016) have identified multiple potential uses for a tornado track estimation product, several questions in our survey sought to determine which developmental product public safety officials preferred most. For each product we asked respondents to indicate how likely they were to use it on a five-point scale ranging from "not at all likely" (one) to "extremely likely" (five). After respondents saw all five products and answered questions about each one individually, we asked them to rank the products overall in terms of usefulness from one (worst) to five (best). While this question did provide somewhat similar information to the earlier question about likely use, it did force respondent's to select their most preferred and least preferred product. This information helped to further differentiate the products, especially since public safety officials tend to view additional information favorably and could have indicated a high likelihood for using all products. From these responses, we scored each of the products based on their likelihood of use and ranking (e.g., a ranking of one was worth one point while a ranking of five was worth five points).

In order, survey respondents indicated that they were most likely to use the 1) NWS track, 2) rotation track, 3) tornado track and intensity, 4) TDS, and 5) maximum Doppler velocity track (Fig. 6a). Similarly, in order from best to worst, survey respondents ranked the usefulness of products as follows: 1) rotation track, 2) NWS track, 3) tornado track and intensity, 4) maximum Doppler velocity track, and 5) TDS (Fig. 6b). Responses to openended questions provided insight into the respondents' reasoning for these rankings and helped to highlight differences in product preferences despite comparable median values for the likelihood of use (Fig. 6a). The NWS track and rotation track were most preferred because they were easy to understand and interpret. Respondents noted that the rotation track did provide additional information about relative intensity and width compared to the NWS track. However, the NWS track was easiest to interpret and provided vital information about where damage may have occurred, so many respondents $(n=79)$ indicated they were extremely likely to use this product. Responses to the open-ended questions did not provide clear answers to why the tornado track and intensity product was preferred less than the NWS track and rotation track. Respondents did report two primary dislikes-use of the EF scale for estimating intensity prior to completion of the official damage survey and lack of tornado width information-that we infer led to the somewhat lower ratings.

The maximum Doppler velocity track and TDS were least preferred primarily because they were hard to understand. Respondents especially singled out the maximum Doppler velocity track as difficult to use. The product was described as vague, muddled, and confusing, and respondents mentioned the need for significant training to use the product successfully. A few respondents $(n=9)$ did like that this product could also be used to identify damaging winds outside of the tornado's circulation (e.g., from strong rearflank downdrafts or downbursts). Additionally, lower rankings for the TDS product arose from misconceptions about what the product actually showed. The most common misconceptions were 1) the product showed debris that was thrown far from the tornado (i.e., debris fallout) and 2) the product only confirmed that a tornado was present but did not show the tornado's approximate track. Respondents who did not have these misconceptions tended to assign a higher ranking to the product. These factors likely contributed to the product's lower median ranking and larger spread in the assigned rankings (Fig. 6b) and were, therefore, a topic that we addressed during the focus group.

\section{b. Focus group results}

Focus group questions were aimed at collecting moredetailed information than was obtained in the online survey. The focus group received additional information about each tornado track estimation product, including situations where each product might work well and when it might fail. We also included questions about radar volumetric update time and its impact on the aforementioned products. 

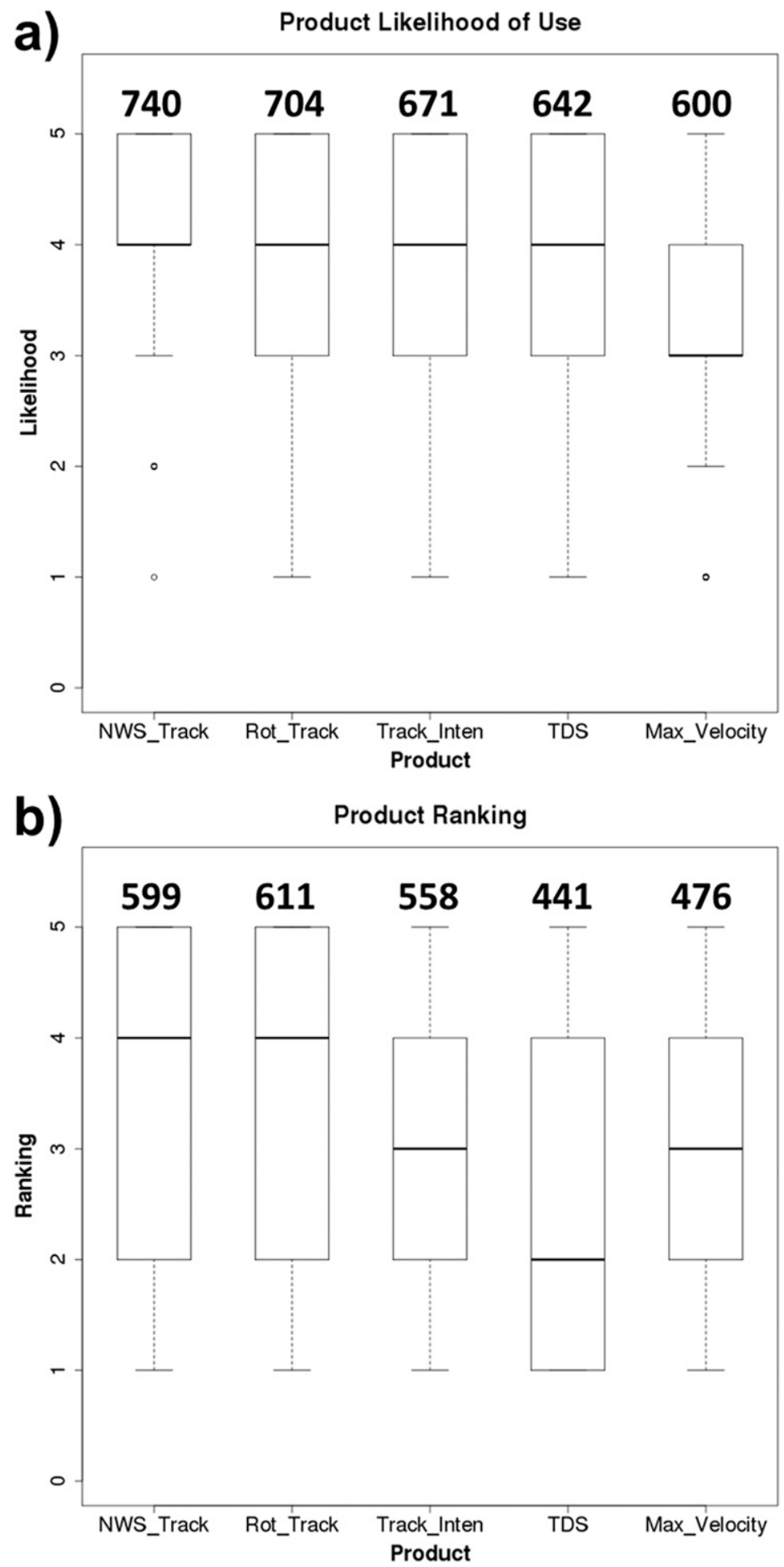

FIG. 6. Box plots showing distribution of survey participants' (a) likelihood of using each product from "not at all likely" (one) to "extremely likely" (five) and (b) ranking of each product from one (worst) to five (best). Boldface numbers represent each product's score calculated by summing the numeric scores provided by the participants. Higher numbers indicate a greater likelihood of use or higher ranking. Box edges are the lower $(\mathrm{Q} 1)$ and upper $(\mathrm{Q} 3)$ quartiles, the horizontal black line is the median, and the lower and upper whiskers represent Q1 $-1.5 \times \mathrm{IQR}$ and Q3 $+1.5 \times \mathrm{IQR}$, respectively, where IQR is the interquartile range. Outliers are indicated by dots. 
Similar to the survey respondents, members of the focus group singled out the NWS track as their most preferred product. This preference arose because they unanimously agreed that it would allow them to quickly identify areas in need of search and rescue teams and disaster-response resources by providing them with the information they need most in the aftermath of a tornado-the location where the tornado occurred and areas that might have sustained damage. They also valued the expert input of NWS forecasters in the product's creation. Such input can improve the product's performance because the forecaster can consider radar limitations as well as other data sources (Karstens et al. 2016). In terms of the tornado track and intensity product, focus group participants did like that it provided additional information about intensity not included in the NWS track, but felt that this information was not critical to search and rescue efforts. Search and rescue teams must address the entire path of the tornado regardless of intensity because injuries can occur even where a tornado is not particularly intense. In addition, the participants had concerns about potential misinterpretation of the EF-scale values included within the tornado track and intensity product by key partners and the general public.

Focus group participants identified the TDS product as their most preferred automated product and second most preferred product overall. This preference differed from the survey results likely because the focus group setting allowed us to more clearly communicate what the product showed, how it was produced, and its strengths and limitations. The focus group participants liked that the product provided confirmation of a tornado via detection of lofted debris. They agreed that knowing the location of lofted debris would give a good idea of where damage had likely occurred and what areas might require assistance. Another attractive aspect of the product to the participants was its near-real-time production. As an automated product, the opportunity exists to produce the product quickly and display it in near-real time in software packages such as OK-FIRST (Morris et al. 2002). The TDS product was also identified during a discussion about the group's ideal tornado track estimation product. One idea included viewing the TDS product along with other radar variables such as reflectivity and velocity in real time. The TDS product could then later be overlaid with the NWS track product when it became available. Focus group participants liked this idea because it provided them with near-real-time information about tornado location as well as expert input provided by the NWS track as soon as it was available.

The focus group unanimously identified the maximum Doppler velocity track product as their least preferred product for a variety of reasons including human factors issues. They felt that the product was cluttered, noisy, hard to interpret, and confusing, which could result in bad decisions such as sending resources to the wrong location. The color scale was also not ideal, though participants said a change in colors would not influence their opinions about the product. Similar to the survey, the focus group pointed to identification of potential wind damage outside of the tornado track as a positive for this product.

After discussing each of the products, we shifted to a discussion about radar update time and its potential role within the public safety official community. Participants were first shown two examples of rapidupdate data-one of a tornadic supercell and the other of a downburst-producing severe thunderstormside by side with conventional-update data. Based on the two cases, participants agreed that rapid-update data would be beneficial to them in general because it painted a better picture of storm movement and intensity trends. We then showed multiple examples of tornado track estimation products produced by rapidupdate data and conventional-update data. Participants unanimously preferred tornado track estimation products produced by rapid-update data because they provided a clearer, more complete picture of what actually happened (Fig. 7a). In contrast, participants felt that products produced with conventional-update data looked incomplete, and it was unclear whether or not the track was produced by a continuous tornado or multiple short-lived tornadoes (Fig. 7c). Despite the preference for the products produced with rapidupdate data, participants agreed that product differences arising from update time would likely not affect their decision-making. For example, they felt that all areas in and around the locations highlighted by the product would be searched. However, participants indicated that they were more likely to use a product created with rapid-update data because it looked more complete to them, which gave them more confidence in using the product to determine where the tornado may have occurred and what homes and infrastructure may have been impacted. Therefore, it is likely that the potential benefits of using a tornado track estimation product would be increased if it is produced with rapidupdate data.

\section{Discussion}

Participants in both the survey and focus group identified multiple situations where a tornado track estimation product could help public safety officials make life-saving decisions. Therefore, it is important for the 

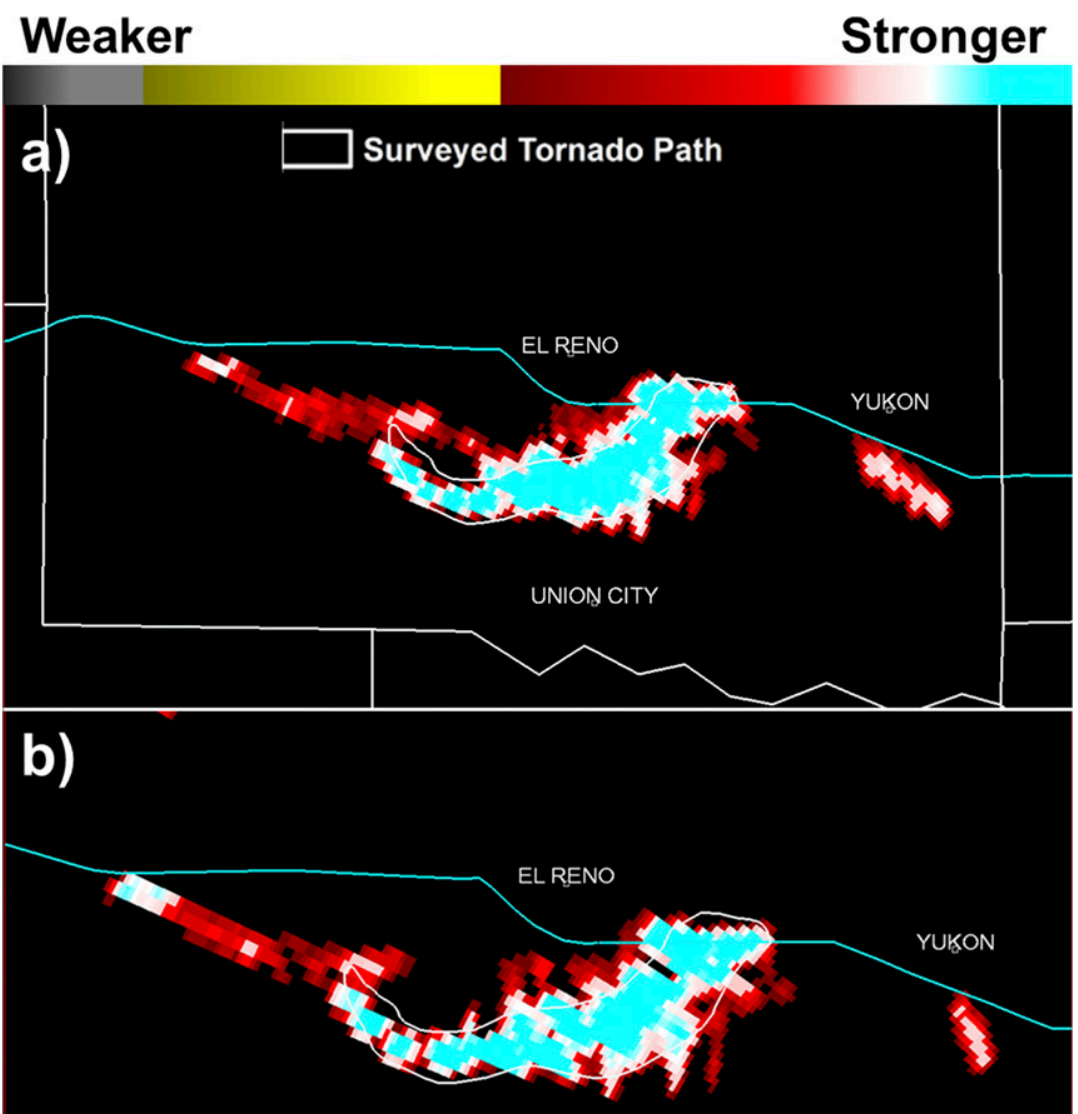

UNION CITY
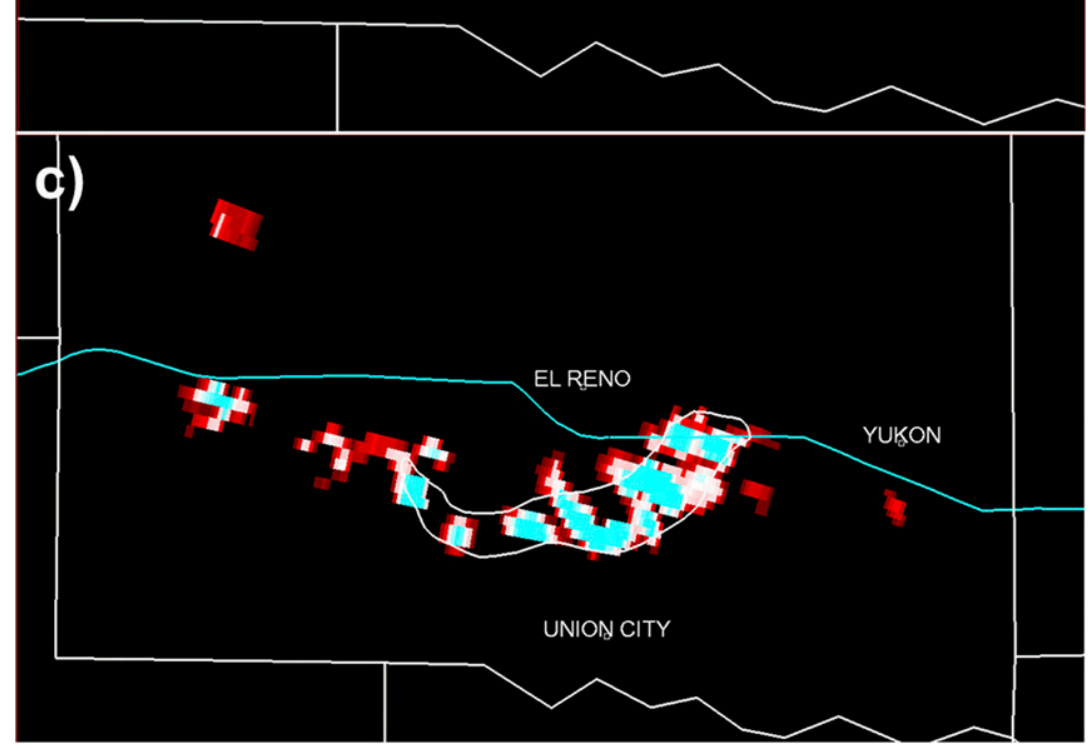

FIG. 7. One example of the rotation track product shown to the focus group produced using (a) 1.7-min KOUN volumetric data, (b) 2.5-min $0.5^{\circ}$ elevation angle data collected by a test radar (KCRI) using SAILS, and (c) 4.6-min WSR-88D (KTLX) volumetric data. The irregular white outline near the center of each image is the surveyed tornado damage path provided by the NWS Forecast Office in Norman. The white lines elsewhere represent county borders, and the light blue line indicates the presence of a major U.S. interstate. A generalized color bar is located at the top. The tornado's range from radar varies from about 46 to $62 \mathrm{~km}$ in (a) and (b) and from about 55 to $74 \mathrm{~km}$ in (c). For the focus group, lower rotation track values were filtered to focus attention on the stronger areas of rotation. 
operational and research meteorology communities to continue the development of such products and include public safety officials in the development process [i.e., coproduction of knowledge; Meadow et al. (2015)]. Participants in the survey and focus group had many similar opinions about the tornado track estimation products. For example, they singled out the NWS track product as being especially useful because it provided essential information in a straightforward manner. Survey and focus group participants did provide differing feedback with respect to the TDS product, however. Survey participants ranked the TDS product as one of their least preferred products, while focus group participants selected the TDS product as their most preferred automated product. The focus group environment provided an opportunity to more clearly communicate what each product displayed and its strengths and weaknesses. This additional information likely contributed to the differing feedback provided by survey and focus group participants. These results point out the need to develop easily understandable products for all decision-makers as well as the need to clearly communicate key information including how each product is created and situations when the product performs well and when it does not.

Survey and focus group participants also highlighted a need for products to be produced as quickly as possible. Participants preferred to have products available in near-real time rather than waiting for a product. Some participants even went as far as saying that a tornado track estimation product would have little use to them if not available in near-real time. In terms of timeliness, the automated products tend to hold an advantage over the manual products. However, public safety officials preferred the manually produced NWS track because of expert input and ease of use. Therefore, the meteorological community should aim to provide public safety officials with a combination of easy-to-use automated and manually created radar-based products, similar to the idea brought forward by the focus group to provide the TDS product in real time and then overlay it with the NWS track when available (section $4 b$ ).

Meteorologists should also consider how products might be shared with public safety officials. Toward this end, we asked respondents about how they might want products sent to them and what file formats would be most preferred. Survey and focus group participants preferred multiple channels of communication (e.g., e-mail, text, and NWS Chat) and file formats (e.g., KML file, shapefile, etc.) that would ultimately allow them to interact with and add information, such as county roads or critical infrastructure, to the products. For example, respondents suggested that the product could be sent via e-mail with an attention-grabbing subject line and at the same time a text message could be sent to each affected party alerting them that the product was completed and ready to view. A KML file and shapefile sent via e-mail would allow recipients to overlay the product with other important geospatial datasets (e.g., storm shelter locations), while an interactive website or smart phone application could allow users to display the product at any location (e.g., incident site). This multipronged approach would allow nearly every public safety official to view and interact with the products regardless of whether he or she had significant experience using a geographic information system (e.g., ArcMap or Google Earth). Additionally, focus group participants stressed the importance of communication using multiple platforms because lines of communication can fail in the aftermath of a disaster.

Previous studies have shown the potential benefits of rapid-update volumetric radar data to NWS forecasters (e.g., Heinselman et al. 2012, 2015; Bowden et al. 2015; Wilson et al. 2017). This work suggests public safety officials will also benefit from more rapidly updating data. Focus group participants unanimously preferred tornado track estimation products created using rapidupdate data. While not a primary topic during the focus group, faster low-level WSR-88D updates currently provided by scanning techniques such as Supplemental Adaptive Intravolume Low-Level Scans (SAILS; Crum et al. 2013) and Multiple Elevation Scan Option for SAILS (MESO-SAILS; ROC 2014) should benefit radar-based product creation and public safety officials using low-level radar data (Fig. 7b). A future system of operational phased-array radars has the capability to provide rapid-update volumetric data to users who look above the lowest elevation angle for information about midlevel rotation or hail cores and for products that rely on volumetric data.

\section{Summary}

The purpose of this study was to involve the public safety official community in the research and development process of radar-based products and future radar systems (e.g., a rapidly updating phased-array radar network). To accomplish this collaboration, we cultivated relationships within the Oklahoma public safety official community by attending meetings, having face-to-face discussions, and presenting at workshops and conferences. We then conducted a weather-radar survey and focus group to collect information from public safety officials regarding their use of radar data, opinions on various developmental tornado track estimation products, ideas for sharing and improving such radar-based products, and first impressions of rapid-update radar 
data and its impact on tornado track estimation products. Through an analysis of the collected responses, we concluded the following:

1) Public safety officials use radar data to support many decisions including placement of storm spotters, activation of outdoor warning sirens, and identifying areas in need of search and rescue teams.

2) Respondents prefer simple, easy-to-use productssuch as the one produced by the Norman NWS Forecast Office (Fig. 1a) — that are provided in near-real time.

3) Clear communication of a product's content, strengths, and weaknesses is essential for effective use and understanding of a product.

4) Respondents prefer multiple methods for being alerted to and receiving the product (e.g., text message alerts, NWS Chat, e-mail, etc.) and multiple file types to display the data in a variety of ways (e.g., ArcMap, Google Earth, interactive website, etc.).

5) Focus group participants indicated that rapid-update radar data provide a clearer picture of storm location and movement and improve the usefulness of tornado track estimation products.

The first conclusion above corroborates findings from past studies on the use of radar data by public safety officials (e.g., Baumgart et al. 2008; League et al. 2010), while the remaining conclusions build upon past work by addressing specific radar-based products and the potential impacts of radar update time. In addition, the information collected through the survey and focus group, along with ongoing interactions with public safety officials, can help product developers refine and improve current and future products. The meteorological community can also use this information in decisions related to radar products and systems. For example, developing straightforward products that quickly and clearly communicate information about the location of a storm's potential impacts to life and property appears to be most useful to public safety officials.

Despite collecting feedback from over 180 public safety officials, we must be aware of the limitations present in our findings. The sample consists primarily of public safety officials from Oklahoma who may have more experience dealing with severe weather than those in other states and may also receive more radar training owing to initiatives and programs such as OK-FIRST (Morris et al. 2002). No survey questions sought to quantify these differences in training or weather-radar knowledge among survey respondents, though it is important to remember that public safety officials have different levels of training, knowledge, and experience in interpreting and using weather radar. These differences may have affected how each respondent answered the survey questions. In addition, radar and its derived products can be challenging to understand and interpret accurately without additional background information. The focus group setting allowed us to present such information, but the survey setting did not, which could have impacted the survey responses. Survey participants also only saw an example of each product produced using a single case of a strong tornado relatively close to the radar. Focus group participants saw multiple examples including weaker tornadoes, but it may have been difficult for survey participants to provide fully informed feedback after seeing only one example. However, this initial study allowed us to step into the public safety official community and open new doors for additional research. Future work could include nationwide or state-specific surveys, focus groups, or experiments with larger sample sizes that address specific weather-related needs or knowledge gaps identified by public safety officials and research meteorologists. These long-term collaborations between researchers and key stakeholdersconsistent with the ideas presented in Meadow et al. (2015) — should advance the knowledge and understanding of both groups, as was demonstrated in this study.

Acknowledgments. The authors thank all of the public safety officials who participated in the survey and focus group and those who welcomed us into the public safety official community. We thank David Ball for setting up contacts within the public safety official community and providing us with opportunities to give presentations about our research. We also thank Jeff Brogden, Karen Cooper, and Robert Toomey for their expertise with WDSSII; Eddie Forren and Brandon Smith for their help with radar data processing; Daphne LaDue and Andrea Melvin for insightful discussions regarding public safety officials and our research; and Alan Gerard, Terry Schuur, and Greg Whitworth for their internal reviews of the manuscript. We also thank four anonymous reviewers for helping us improve the quality of this manuscript. Funding for CK, JS, and KW was provided by NOAA/Office of Oceanic and Atmospheric Research under NOAA-University of Oklahoma Cooperative Agreement NA11OAR4320072, U.S. Department of Commerce.

\section{REFERENCES}

Baumgart, L. A., E. J. Bass, B. Philips, and K. Kloesel, 2008: Emergency management decision making during severe weather. Wea. Forecasting, 23, 1268-1279, doi:10.1175/2008WAF2007092.1.

Biernacki, P., and D. Waldorf, 1981: Snowball sampling. Sociol. Methods Res., 10, 141-163, doi:10.1177/004912418101000205.

Biggs, S. D., 1989: Resource-poor farmer participation in research: A synthesis of experiences from nine national agricultural 
research systems. OFCOR Comparative Study Paper 3, International Service for National Agricultural Research, 37 pp., http://ebrary.ifpri.org/cdm/ref/collection/p15738coll11/id/92.

Bluestein, H. B., J. C. Snyder, and J. B. Houser, 2015: A multiscale overview of the El Reno, Oklahoma, tornadic supercell of 31 May 2013. Wea. Forecasting, 30, 525-552, doi:10.1175/ WAF-D-14-00152.1.

Bowden, K. A., P. L. Heinselman, D. M. Kingfield, and R. P. Thomas, 2015: Impacts of phased-array radar data on forecaster performance during severe hail and wind events. Wea. Forecasting, 30, 389-404, doi:10.1175/WAF-D-14-00101.1.

Brown, R. A., and V. T. Wood, 2012: The tornado vortex signature: An update. Wea. Forecasting, 27, 525-530, doi:10.1175/ WAF-D-11-00111.1.

_ L. R. Lemon, and D. W. Burgess, 1978: Tornado detection by pulsed Doppler radar. Mon. Wea. Rev., 106, 29-38, doi:10.1175/ 1520-0493(1978)106<0029:TDBPDR > 2.0.CO;2.

_ , V. T. Wood, and D. Sirmans, 2002: Improved tornado detection using simulated and actual WSR-88D data with enhanced resolution. J. Atmos. Oceanic Technol., 19, 1759-1771, doi:10.1175/ 1520-0426(2002)019<1759:ITDUSA > 2.0.CO;2.

Burgess, D. W., R. J. Donaldson Jr., and P. R. Desrochers, 1993: Tornado detection and warning by radar. The Tornado: Its Structure, Dynamics, Prediction and Hazards, Geophys. Monogr., Vol. 79, Amer. Geophys. Union, 203-221.

__ , and Coauthors, 2014: 20 May 2013 Moore, Oklahoma, tornado: Damage survey and analysis. Wea. Forecasting, 29, 1229-1237, doi:10.1175/WAF-D-14-00039.1.

Crum, T. D., S. D. Smith, J. N. Chrisman, R. E. Saffle, R. W. Hall, and R. J. Vogt, 2013: WSR-88D radar projects-Update 2013 29th Conf. on Environmental Information Processing Technologies, Austin, TX, Amer. Meteor. Soc., 8.1, https://ams. confex.com/ams/93Annual/webprogram/Paper221461.html.

Doswell, C. A., III, H. E. Brooks, and N. Dotzek, 2009: On the implementation of the enhanced Fujita scale in the USA. Atmos. Res., 93, 554-563, doi:10.1016/j.atmosres.2008.11.003.

Forsyth, D. E., and Coauthors, 2005: The National Radar Testbed (Phased-Array). 32nd Conf. on Radar Meteorology, Albuquerque, NM, Amer. Meteor. Soc., 5.21, http://ams.confex. com/ams/pdfpapers/30559.pdf.

Heinselman, P. L., and S. M. Torres, 2011: High-temporal-resolution capabilities of the National Radar Testbed Phased-Array Radar. J. Appl. Meteor. Climatol., 50, 579-593, doi:10.1175/ 2010JAMC2588.1.

— D. S. LaDue, and H. Lazrus, 2012: Exploring impacts of rapid-scan radar data on NWS warning decisions. Wea. Forecasting, 27, 1031-1044, doi:10.1175/WAF-D-11-00145.1.

- — D. M. Kingfield, and R. Hoffman, 2015: Tornado warning decisions using phased-array radar data. Wea. Forecasting, 30, 57-78, doi:10.1175/WAF-D-14-00042.1.

Jasanoff, S., and B. Wynne, 1998: Science and decisionmaking. Human Choice and Climate Change, S. Raymer and E. L. Malone, Eds., Battelle Press, 1-87.

Karstens, C. D., and Coauthors, 2015: Evaluation of a probabilistic forecasting methodology for severe convective weather in the 2014 Hazardous Weather Testbed. Wea. Forecasting, 30,15511570, doi:10.1175/WAF-D-14-00163.1.

- and Coauthors, 2016: Evaluation of near real-time preliminary tornado damage paths. J. Oper. Meteor., 4, 132-141, doi:10.15191/nwajom.2016.0410.

Kingfield, D. M., and J. G. LaDue, 2015: The relationship between automated low-level velocity calculations from the WSR-88D and maximum tornado intensity determined from damage surveys. Wea. Forecasting, 30, 1125-1139, doi:10.1175/ WAF-D-14-00096.1.

LaDue, D. S., S. Ernst, C. D. Karstens, J. Correia Jr., J. E. Hocker, and J. P. Wolfe, 2016: Co-creating the form and function of the prototype probabilistic hazard information (PHI) to meet emergency manager user needs. 11th Symp. on Societal Applications, New Orleans, LA, Amer. Meteor. Soc., 7.4, https://ams. confex.com/ams/96Annual/webprogram/Paper280331.html.

LaDue, J. G., K. L. Ortega, B. R. Smith, G. J. Stumpf, and D. M. Kingfield, 2012: A comparison of high resolution tornado surveys to Doppler radar observed mesocyclone parameters: 2011-2012 case studies. 26th Conf. on Severe Local Storms, Nashville, TN, Amer. Meteor. Soc., 6.3, https://ams.confex. com/ams/26SLS/webprogram/Paper212627.html.

League, C. E., W. Díaz, B. Philips, E. J. Bass, K. Kloesel, E. Gruntfest, and A. Gessner, 2010: Emergency manager decision-making and tornado warning communication. Meteor. Appl., 17, 163-172, doi:10.1002/met.201.

Lemos, C. M., and B. J. Morehouse, 2005: The co-production of science and policy in integrated climate assessments. Global Environ. Change, 15, 57-68, doi:10.1016/j.gloenvcha.2004.09.004.

Manross, K. L., T. M. Smith, J. T. Ferree, and G. J. Stumpf, 2008: An on-demand user interface for requesting multi-radar, multi-sensor time accumulated products to support severe weather verification. 24th Conf. on Interactive Information Processing Systems, New Orleans, LA, Amer. Meteor. Soc., P2.13, https://ams.confex.com/ams/pdfpapers/134621.pdf.

Meadow, A. M., D. B. Ferguson, Z. Guido, A. Horangic, G. Owen, and T. Wall, 2015: Moving toward the deliberate coproduction of climate science knowledge. Wea. Climate Soc., 7, 179-191, doi:10.1175/WCAS-D-14-00050.1.

Miller, M. L., V. Lakshmanan, and T. M. Smith, 2013: An automated method for depicting mesocyclone paths and intensities. Wea. Forecasting, 28, 570-585, doi:10.1175/WAF-D-12-00065.1.

Morris, D. A., K. C. Crawford, K. A. Kloesel, and G. Kitch, 2002: OK-FIRST: An example of successful collaboration between the meteorological and emergency response communities on 3 May 1999. Wea. Forecasting, 17, 567-576, doi:10.1175/ 1520-0434(2002)017<0567:OFAEOS $>2.0$. CO;2.

Park, H., A. V. Ryzhkov, D. S. Zrnić, and K. Kim, 2009: The hydrometeor classification algorithm for the polarimetric WSR-88D: Description and application to an MCS. Wea. Forecasting, 24, 730-748, doi:10.1175/2008WAF2222205.1.

Piltz, S. F., and D. W. Burgess, 2009: The impacts of thunderstorm geometry and WSR-88D beam characteristics on diagnosing supercell tornadoes. 34th Conf. on Radar Meteorology, Williamsburg, VA, Amer. Meteor. Soc., P6.18, https://ams. confex.com/ams/pdfpapers/155944.pdf.

ROC, 2014: MESO-SAILS (Multiple Elevation Scan Option for SAILS) initial description document. NOAA/NWS/Radar Operations Center Rep., 4 pp., https://www.roc.noaa.gov/ WSR88D/PublicDocs/NewTechnology/MESO-SAILS_Intial_ Description_v02_Feb_2014.pdf.

Smith, B. T., R. L. Thompson, A. R. Dean, and P. T. Marsh, 2015: Diagnosing the conditional probability of tornado damage rating using environmental and radar attributes. Wea. Forecasting, 30, 914-932, doi:10.1175/WAF-D-14-00122.1.

Snyder, J. C., and H. B. Bluestein, 2014: Some considerations for the use of high-resolution mobile radar data in tornado intensity determination. Wea. Forecasting, 29, 799-827, doi:10.1175/WAF-D-14-00026.1.

, and A. V. Ryzhkov, 2015: Automated detection of polarimetric tornadic debris signatures using a hydrometeor classification 
algorithm. J. Appl. Meteor. Climatol., 54, 1861-1870, doi:10.1175/ JAMC-D-15-0138.1.

Speheger, D. A., and R. D. Smith, 2006: On the imprecision of radar signature locations and storm path forecasts. Natl. Wea. Dig., 30, 3-10.

Stumpf, G. J., T. M. Smith, K. Manross, and D. L. Andra, 2008: The Experimental Warning Program 2008 Spring Experiment at the NOAA Hazardous Weather Testbed. 24th Conf. on Severe Local Storms, Savannah, GA, Amer. Meteor. Soc., 8A.1, http://ams.confex.com/ams/pdfpapers/ 141712.pdf.

Toth, M., R. J. Trapp, J. Wurman, and K. A. Kosiba, 2013: Comparison of mobile-radar measurements of tornado intensity with corresponding WSR-88D measurements. Wea. Forecasting, 28, 418-426, doi:10.1175/WAF-D-12-00019.1.

Van Den Broeke, M. S., and S. T. Jauernic, 2014: Spatial and temporal characteristics of polarimetric tornadic debris signatures. J. Appl. Meteor. Climatol., 53, 2217-2231, doi:10.1175/ JAMC-D-14-0094.1.
Weaver, J., L. C. Harkabus, J. Braun, S. Miller, R. Cox, J. Griffith, and R. J. Mazur, 2014: An overview of a demographic study of United States emergency managers. Bull. Amer. Meteor. Soc., 95, 199-203, doi:10.1175/BAMS-D-12-00183.1.

Wilson, K. A., P. L. Heinselman, C. M. Kuster, D. M. Kingfield, and Z. Khang, 2017: Forecaster performance and workload: Does radar update time matter? Wea. Forecasting, 32, 253-274, doi:10.1175/WAF-D-16-0157.1.

Wood, V. T., R. A. Brown, and D. Sirmans, 2001: Technique for improving detection of WSR-88D mesocyclone signatures by increasing angular sampling. Wea. Forecasting, 16, 177-184, doi:10.1175/1520-0434(2001)016<0177:TFIDOW>2.0.CO;2.

Zhang, J., and Coauthors, 2016: Multi-Radar Multi-Sensor (MRMS) quantitative precipitation estimation: Initial operating capabilities. Bull. Amer. Meteor. Soc., 97, 621-638, doi:10.1175/BAMS-D-14-00174.1.

Zrnić, D. S., and Coauthors, 2007: Agile-beam phased array radar for weather observations. Bull. Amer. Meteor. Soc., 88, 17531766, doi:10.1175/BAMS-88-11-1753. 